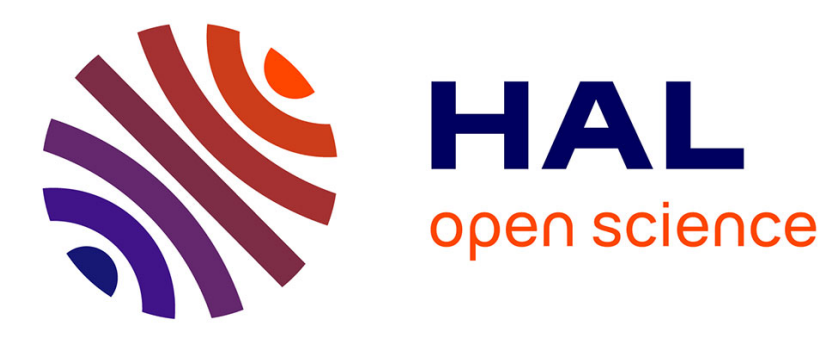

\title{
Fluctuating thermal regime preserves physiological homeostasis and reproductive capacity in Drosophila suzukii
}

Clayre Grumiaux, Mads Kuhlmann Andersen, Hervé Colinet, Johannes

Overgaard

\section{To cite this version:}

Clayre Grumiaux, Mads Kuhlmann Andersen, Hervé Colinet, Johannes Overgaard. Fluctuating thermal regime preserves physiological homeostasis and reproductive capacity in Drosophila suzukii. Journal of Insect Physiology, 2019, 113, pp.33-41. 10.1016/j.jinsphys.2019.01.001 hal-02019347

\section{HAL Id: hal-02019347 \\ https://hal-univ-rennes1.archives-ouvertes.fr/hal-02019347}

Submitted on 4 Apr 2019

HAL is a multi-disciplinary open access archive for the deposit and dissemination of scientific research documents, whether they are published or not. The documents may come from teaching and research institutions in France or abroad, or from public or private research centers.
L'archive ouverte pluridisciplinaire HAL, est destinée au dépôt et à la diffusion de documents scientifiques de niveau recherche, publiés ou non, émanant des établissements d'enseignement et de recherche français ou étrangers, des laboratoires publics ou privés. 


\section{Fluctuating thermal regime preserves physiological homeostasis and reproductive capacity in Drosophila suzukii}

\section{Clayre Grumiaux ${ }^{1}$, Mads Kuhlmann Andersen ${ }^{1}$, Hervé Colinet $^{2}$ and Johannes Overgaard ${ }^{1, *}$}

\footnotetext{
${ }^{1}$ Zoophysiology, Department of Bioscience, Aarhus University, 8000 Aarhus C, Denmark

${ }^{2}$ Université Rennes 1, CNRS, ECOBIO - UMR 6553, 263 Avenue du Général Leclerc, 35042 Rennes, France
}

*Author for correspondence: johannes.overgaard@bios.au.dk

Keywords: Fluctuating thermal regimes, biological control, cold tolerance, insect storage, insect rearing, ion balance 


\begin{abstract}
Drosophila suzukii, an invasive species recently introduced in Europe, lays eggs in thin-skinned fruits and causes huge financial losses to fruit growers. One potential way to control this pest is the sterile insect technique (SIT) which demands a large stock of reproductive females to produce millions of sterile males to be released on demand. Unfortunately, Drosophila stocks age quickly, show declining fecundity when maintained at warm temperatures and conversely, they die from chill injury if they are maintained at constant low temperature. Here we investigate the potential of fluctuating thermal regime (FTR) as a storage method that harness the benefits of both warm and cold storage. Using a FTR regime with a daily warm period $\left(1 \mathrm{~h} 20\right.$ at $\left.25^{\circ} \mathrm{C}\right)$ and cold period $(20$ hours at $3^{\circ} \mathrm{C}$ ), interspaced by gradual heating and cooling, we compared longevity, fecundity and physiological condition between FTR females and females exposed to constant $25^{\circ} \mathrm{C}$ and $3^{\circ} \mathrm{C}$. As hypothesised, FTR flies experienced much slower senescence (more than 3-fold increase in lifespan) and they preserved fecundity to a much higher age than flies from constant $25^{\circ} \mathrm{C}$. Flies maintained at constant $3^{\circ} \mathrm{C}$ quickly died from chill injuries caused by a gradual loss of ion and water balance. In contrast, FTR flies were able to maintain ion and water balance (similar to $25^{\circ} \mathrm{C}$ flies) as they were allowed to recover homeostasis during the short warm periods. Together these results demonstrate that FTR represents a useful protocol for storage of Drosophila stocks, and more broadly, this shows that the benefits of FTR are tightly linked with the insect ability to recover physiological homeostasis during the short warm periods.
\end{abstract}




\section{Introduction}

As a consequence of globalisation and increased international trade, insect species have often been introduced accidentally into new habitats (Ascunce et al., 2011; Desneux et al., 2010). One of these invasive species, Drosophila suzukii (Matsumura) (Diptera: Drosophilidae) originates from SouthEast Asia but has recently been introduced in Europe and Northern America (Cini et al., 2012). Most Drosophila species lay eggs on rotten fruit, but D. suzukii females possess a large serrated ovipositor allowing them to also lay their eggs in healthy thin-skinned fruits such as cherries or blueberries (Kanzawa, 1939). Once the larvae feed on the fruit flesh it becomes unsaleable, and infestations of D. suzukii therefore incur substantial economic loss associated with loss of crops, pest management and fruit selection (Bolda et al., 2010; Goodhue et al., 2011; Lee et al., 2011). A potential method to control pest insects such as D. suzukii is the sterile insect technique (SIT) where huge numbers of sterile males are released to outcompete fertile males that have invaded agricultural areas (Hendrichs and Robinson, 2009). The use of SIT, classical biocontrol, as well as incompatible insect technique (Zabalou et al., 2009) are currently under investigation in D. suzukii (Nikolouli et al., 2017) and it is therefore of interest to study how rearing and storing of this species can be optimised

Insects used in biological control are often stored at low temperatures as this limits senescence and reduces the labour associated with maintenance. However, most Drosophila species, including D. suzukii, are chill-susceptible, and succumb during chronic exposure to low or even mild temperatures (Andersen et al., 2015; Dalton et al., 2011; Enriquez and Colinet, 2017; Jakobs et al., 2015; Kimura, 2004; MacMillan et al., 2015b; Plantamp et al., 2016; Ryan et al., 2016). When chill susceptible Drosophila are exposed to chronic low temperature they decrease their activity and if the temperature is sufficiently low they enter a coma. Short exposures to cold coma do not cause physiological damage, but during chronic expose the active transport of ions becomes supressed to a degree that is insufficient to balance the passive leak of ions across cell membranes or epithelia (Koštál et al., 2004; MacMillan and Sinclair, 2011; Overgaard and MacMillan, 2017). Imbalance of active vs. passive ion transport will lead to a characteristic increase in extracellular potassium that depolarises the cells, and cause cell death (Bayley et al., 2018; MacMillan et al., 2015c). Further, it is clear that comatose insects are unable to feed and drink and they may therefore also suffer from a reduction in energy stores or water content which can ultimately compromise survival (Koštál et al., 2016). 
Maintenance of Drosophila species under standard rearing conditions $\left(20-25^{\circ} \mathrm{C}\right)$ is also problematic as Drosophila generally have a short lifespan at such temperatures and they will also quickly experience a reduction of fecundity (Curtsinger, 2013; David et al., 1975; Lin et al., 2014). Rearing under standard/benign conditions and the maintenance of repeated generations will therefore be demanding in time and resource. Fluctuating thermal regimes (FTR) represent a potential way of mitigating the effects of both constant high and low temperature exposure as this artificial temperature regime alternates the extensive exposure to low temperature with short periods of warm temperature (Colinet et al., 2018, 2015). FTR treatments may be very useful as an efficient protocol for promoting insect cold-survival and longevity in large insect rearing programs (Colinet et al., 2018; Colinet and Hance, 2009; Koštál et al., 2016). FTR has been used in several insect species (Colinet et al., 2016; Koštál et al., 2007; Rinehart et al., 2000) and has proven to increase shelf-life and cold-survival in several other species, including Drosophila melanogaster and $D$. suzukii (Colinet et al., 2016; Enriquez et al., 2018; Javal et al., 2016; Nedvěd et al., 1998; Renault et al., 2004).

These benefits of FTR are linked to the short warm periods which allow the insect to recover or prevent the development of chill injuries related to constant cold exposure. Evidence from transcriptomic, metabolomic, and lipidomic studies points to system-wide loss of homeostasis at low temperature that can be counterbalanced by repair mechanisms under FTR (Colinet et al., 2016; Torson et al., 2015). This is also supported by physiological studies of Pyrrhocoris apterus, Alphitobius diaperinus and Drosophila melanogaster larvae that demonstrate how re-establishment of active transport during the short warm periods was sufficient to re-establish ion gradients that were partially dissipated during the cold period (Koštál et al., 2016, 2007). Furthermore, data from Drosophila larvae indicate that resumption of feeding during warm periods helps to preserve energy stores compared to larvae maintained at constant low temperature (CLT) (Koštál et al., 2016). The positive effects of FTR may therefore also be linked to the insects' ability to preserve or recover its water balance and energy stores during the short warm periods (Boardman et al., 2013).

In the present study, we examine the impact of the FTR on D. suzukii performance in several experiments designed to assess FTR effects on longevity, fecundity, thermal tolerance, ion homeostasis and body composition. In doing so, we compared responses of flies exposed to FTR with flies reared either at standard rearing temperature or CLT. The aim of these experiments was to investigate if 1) FTR can avoid the drawbacks of maintenance under normal rearing conditions in 
terms of reducing senescence and retaining fecundity, and 2) FTR can mitigate cold-induced perturbations of ion and energy balance that is often associated with mortality at CLT.

\section{Material \& Methods}

\section{Animal husbandry}

Drosophila suzukii used in the present study were imported from the CNRS Ecobio unit in 2017 (Rennes, France). This stock culture of D. suzukii flies was established from a field collection of populations on blueberries and raspberries in Thorigné Fouillard, France (48³'41.76' N $1^{\circ} 14$ '19.32'E) in September 2016. The parental fly stock was maintained in $250 \mathrm{~mL}$ plastic bottles containing $50 \mathrm{~mL}$ of Leeds medium (for $1 \mathrm{~L}$ of water: $60 \mathrm{~g}$ of yeast, $40 \mathrm{~g}$ of sucrose, $30 \mathrm{~g}$ of oatmeal, $16 \mathrm{~g}$ of agar, $12 \mathrm{~mL}$ of methylparaben and $1.2 \mathrm{~mL}$ of acetic acid). Flies were kept in a room at $25 \pm 1{ }^{\circ} \mathrm{C}, \sim 70 \% \mathrm{RH}$ and a $12 \mathrm{~L}: 12 \mathrm{D}$ light/dark regime where adults were transferred to new food bottles every 2-3 days. Used bottles containing eggs were used to establish the following generation and were stored under similar conditions until emergence. Flies used for experiments were maintained for 7 days after which flies were sexed without use of anaesthesia and the females were then used for further experiments.

\section{Experimental protocol}

Seven days old females were placed into $50 \mathrm{~mL}$ vials with $7 \mathrm{~mL}$ fly media $(\mathrm{n}=20-25$ females per vial) and exposed to one of three thermal regimes in either temperature rooms or temperature cabinets. The thermal regimes were: constant $25^{\circ} \mathrm{C}$ (similar to rearing conditions), constant $3^{\circ} \mathrm{C}$ (or CLT), or a fluctuating thermal regime (FTR) consisting of daily cycles of $20 \mathrm{~h}$ at $3{ }^{\circ} \mathrm{C}, 1 \mathrm{~h} 20$ of ramping to $25^{\circ} \mathrm{C}, 1 \mathrm{~h} 20$ at $25^{\circ} \mathrm{C}$ and $1 \mathrm{~h} 20$ of ramping to $3^{\circ} \mathrm{C}$ (Fig. 1). These temperature regimes were chosen based on previous experience showing that $20{ }^{\circ} \mathrm{C}$ is a benign temperature and that $3{ }^{\circ} \mathrm{C}$ causes the flies to enter a cold coma and where chill injury gradually develop (Enriquez et al., 2018; Enriquez and Colinet, 2017).

All thermal regimes had a 12L:12D light cycle and temperature was regularly checked using a temperature data logger (iButton Thermochron, Embedded Data Systems, Lawrenceburg, US). To test the effects of these different thermal regimes on $D$. suzukii females, we ran several experiments allowing us to investigate longevity, fecundity, thermal tolerance, haemolymph potassium concentration and body composition. The time at which flies were sampled for the different 
experiments is outlined in Fig. 2 and the details of the experimental protocols can be found in the sections below.

\section{Longevity during maintenance at constant $3^{\circ} \mathrm{C}$, constant $25^{\circ} \mathrm{C}$ and FTR}

Different protocols were used to assess longevity during exposure at constant $3{ }^{\circ} \mathrm{C}$ compared to flies exposed to constant $25^{\circ} \mathrm{C}$ or FTR conditions. Flies exposed to constant $3{ }^{\circ} \mathrm{C}$ were comatose and could therefore not be scored for longevity unless they were removed from the treatment and allowed to recover from the coma at benign temperature. Accordingly, flies from constant $3^{\circ} \mathrm{C}(\mathrm{N}=$ 100 per day) were removed from the treatment (every day from day 1 to 7 ) and then placed at $25^{\circ} \mathrm{C}$ in food vials for $24 \mathrm{~h}$ before survival was scored. Flies maintained at FTR or constant $25^{\circ} \mathrm{C}$ conditions could be monitored continuously (FTR flies were checked during the warm period when the flies were active). For these treatments longevity was examined on the same cohort of 200 flies every day from day 1-10 (stored in 10 vials with 20 individuals per vial). After day 10 survival was recorded weekly, until all flies were dead or until day 160 when the experiment was terminated. Dead individuals were discarded, and live individuals were put in a new food vials every third day.

\section{Fecundity}

Fecundity was estimated by recording egg production of individuals that had been exposed for 10, 20, 30 and 40 days of constant $25^{\circ} \mathrm{C}$ or FTR (fecundity was not measured for constant $3^{\circ} \mathrm{C}$, as these flies survived < 10 days in this treatment). Egg production was scored daily over a 10-day period after the flies had been removed from the rearing treatment and put at constant $25^{\circ} \mathrm{C}$. Each female ( $\mathrm{N}=10$ per combination of duration of exposure and treatment) was placed with two mature males inside a vial containing a small spoon filled with fly food. Every day, the spoons were replaced and so were the male flies to ensure that these were always in a good reproductive state. Eggs laid were counted each day under a microscope and egg production was then summed over a 10-day period.

\section{Temperature tolerance assays}

Cold tolerance was assessed at different timepoints during the exposure to the three thermal regimes. This was done by measuring chill coma recovery time (CCRT) following a stressful cold exposure for $14 \mathrm{~h}$ at $0^{\circ} \mathrm{C}(\mathrm{N}=90$ flies per duration of exposure and per thermal regime: constant 3, $25^{\circ} \mathrm{C}$ or FTR). CCRT was measured on female flies pre-exposed for 1 to 7 days to either constant 
$3^{\circ} \mathrm{C}$, constant $25^{\circ} \mathrm{C}$ or FTR. For each treatment/temperature combination flies were put inside a Falcon tube with a styrofoam lid to ensure ventilation, FTR flies were placed in the Falcon tubes during the cold period, 4-6h after the last warm period. Flies were then placed at $0^{\circ} \mathrm{C}$ for $14 \mathrm{~h}$ in a bath filled with an ice/water slurry. After this cold exposure flies were taken out of the tube and placed on their back on a piece of paper at room temperature (approximately $25^{\circ} \mathrm{C}$ ). Flies were observed for up to $90 \mathrm{~min}$ and the time until the flies returned to a standing position was then recorded as the CCRT. Flies that had not recovered after 90 min were removed from the CCRT dataset.

In a different set of experiments, we also estimated thermal tolerance of the treatment groups by assessing chill-coma onset temperature ( $\mathrm{CCO}$ - sometimes referred to as $\left.\mathrm{CT}_{\min }\right)$ and heat-coma onset ( $\mathrm{HCO}$ - sometimes referred to as $\mathrm{CT}_{\max }$ ) of females exposed 27 days to either constant $25^{\circ} \mathrm{C}$ or FTR ( $\mathrm{N}=20$ flies per thermal regime). The CCO test was performed by placing individuals in $4 \mathrm{~mL}$ glass vials which were submerged in a bath (mix of water and ethylene glycol; $1: 1$ ) set at $25^{\circ} \mathrm{C}$ using a refrigerated circulator heater (Lauda RE320, Lauda-Königshofen, Germany). FTR individuals were placed inside the glass vials at the end of the cold period. Temperature was then lowered by $0.2^{\circ} \mathrm{C} / \mathrm{min}$ and $\mathrm{CCO}$ was recorded as the temperature at which the flies lost the ability to move. Vials were gently tapped at regular intervals along the ramping. The heat-coma onset (HCO) test was performed the same way, except temperature was ramped up by $0.2^{\circ} \mathrm{C} / \mathrm{min}$.

\section{Hemolymph potassium concentration}

Increasing hemolymph potassium concentration is a good indicator for the development of chill injury in Drosophila (MacMillan et al., 2015). Here we obtained hemolymph samples by antennal ablation as described by MacMillan and Hughson (2014). Flies ( $\mathrm{N}=10-15$ per treatment condition) were sampled from their holding condition immediately before the hemolymph was sampled. To do so, FTR and constant $3^{\circ} \mathrm{C}$ flies were loaded into pipette tips the day before the extraction to speed up sampling. Measurement of hemolymph potassium concentration was performed using ion selective microelectrodes (see MacMillan et al., 2015 for information on production of ion sensitive electrodes). Potassium activity was obtained from voltage measurements which were converted to ion concentrations through reference to calibration solutions using the following equation:

$$
[h]=[c] \times 10^{\left(\frac{\Delta V}{S}\right)}
$$


where $[\mathrm{h}]$ is the active ion concentration in the hemolymph, $[\mathrm{c}]$ is the concentration in one of the calibration solutions, $\Delta \mathrm{V}$ is the voltage difference between the calibration solution and hemolymph, and $\mathrm{S}$ is the slope of the voltage response to the ten-fold concentration difference in the calibration solutions. Further, only electrodes with slopes between 50 and $62 \mathrm{mV}$ were used for experiments.

\section{Body mass and body composition (water and lipid content)}

Flies were sampled at regular intervals to assess the effects of storage conditions on body mass and body composition of females $(\mathrm{N}=60$ flies per duration of exposure and treatment, with 12 replicates of 5 flies and see Fig. 2 for sampling intervals). After collection, flies were killed by exposure to $-80^{\circ} \mathrm{C}$ and they were then stored at this temperature until further measurements. Each measurement was done by pooling flies in groups of five, and then by dividing the weight obtained in each group by the number of flies composing it to obtain the weight corresponding to one fly.

\section{Wet mass and dry mass}

Flies from each treatment group were pooled in groups of five, weighed using a precision scale (Sartorius MSE6.65, Sartorius Lab Instruments GmbH \& Co. KG, Göttingen, Germany) to obtain the wet mass. They were then placed in open Eppendorf tubes and dried for $48 \mathrm{~h}$ in a $60^{\circ} \mathrm{C}$ incubator after which they were weighed again to obtain dry mass. Water content was calculated by subtracting the dry mass from the wet mass and the dried flies were then placed in perforated aluminium containers for lipid extraction.

\section{Lipid content}

Using a method similar to the one described in Luque de Castro and Priego-Capote (2010), lipid was removed from the samples using a Soxhlet apparatus which repeatedly washes the samples with petroleum ether for $72 \mathrm{~h}$. After lipid removal the samples were returned to the $60^{\circ} \mathrm{C}$ incubator to dry for $24 \mathrm{~h}$ and re-weighed to obtain the lean dry mass. Lipid content was calculated by subtracting the lean dry mass from the dry mass.

\section{Statistical analysis}

All the analyses were done using $\mathrm{R}$ software ( $\mathrm{R}$ version 3.4.0). Longevity was compared among treatments using a Mantel-Cox analysis. To test if there were any effects of thermal regime or 
treatment duration on fecundity, we used a generalised linear model with a Poisson-distributed error-distribution to compare the overall egg-laying pattern, followed by a two-way ANOVA to analyse the effects of the three thermal regimes and pairwise t-tests for multiple comparisons with Bonferroni correction applied. Data on CCRT, ion concentration, wet mass and water and lipid content were analysed using two-way ANOVAs and pairwise t-tests with Bonferroni correction were used to compare treatments and time points. For wet mass, water content and lipid content, the analysis was performed twice, depending on the duration of exposure. It was first performed to compare all three treatments (constant $25^{\circ} \mathrm{C}$, constant $3{ }^{\circ} \mathrm{C}$ and FTR) for the first 10 days of exposure, and then a second time to compare only the constant $25^{\circ} \mathrm{C}$ and FTR treatments for the whole 40 days of exposure (flies exposed to constant $3^{\circ} \mathrm{C}$ were all found dead after 10 days of exposure). Data on CCO and HCO were analysed using a Mann-Whitney-Wilcoxon test, as the data did not meet the criteria of normal distribution. The critical level for statistical significance was 0.05 in all analyses and values presented are means with accompanying standard errors unless stated otherwise.

\section{Results}

\section{Effect of storage conditions on longevity of Drosophila suzukii}

Females exposed to constant $3^{\circ} \mathrm{C}$ had a shorter longevity than the other treatments (Log-rank Test: $3^{\circ} \mathrm{C}$ vs $25^{\circ} \mathrm{C}: \chi^{2}=300, \mathrm{df}=1, \mathrm{P}<0.001 ; 3^{\circ} \mathrm{C}$ ss FTR: $\left.\chi^{2}=189, \mathrm{df}=1, \mathrm{P}<0.001\right)$ and FTR females had the highest longevity (Log-rank Test: $25^{\circ} \mathrm{C} v s$ FTR: $\chi^{2}=67$, df $=1, \mathrm{P}<0.001$ ) with $\sim 50 \%$ of FTR females still alive after 160 days (Fig. 3).

\section{Effect of storage conditions on fecundity of Drosophila suzukii}

Only females from constant $25^{\circ} \mathrm{C}$ and FTR temperature regimes were used in this experiment, as constant $3^{\circ} \mathrm{C}$ females could not survive until the first day of fecundity assessment (Day 10). The duration of exposure (two-way ANOVA, $\chi^{2}=550.81$, $\mathrm{df}=3, \mathrm{P}<0.001$ ) and the thermal regime (twoway ANOVA, $\chi^{2}=8.93$, df $=1, \mathrm{P}<0.05$ ) both had significant effects on egg laying capacity. Furthermore, there was a significant interaction between these two factors (two-way ANOVA, $\chi^{2}=$ 388.90 , df $=3, \mathrm{P}<0.001$ ) such that constant $25^{\circ} \mathrm{C}$ females laid fewer eggs with increasing age while FTR flies maintained egg laying rate over time (Fig. 4). 


\section{Effect of storage conditions on temperature tolerance of Drosophila suzukii}

\section{Chill coma recovery time}

Flies were tested for CCRT at various time points whilst subjected to the three thermal regimes (Fig. 2). Exposure time had a major effect on the CCRT of both $3{ }^{\circ} \mathrm{C}, 25^{\circ} \mathrm{C}$, and FTR females (twoway ANOVA, $\left.\mathrm{F}_{1,1316}=126.2, \mathrm{P}<0.001\right)$. Females exposed to FTR were able to return to an upright position quicker than flies exposed to constant $25^{\circ} \mathrm{C}$ or $3^{\circ} \mathrm{C}$ (two-way ANOVA, $\mathrm{F}_{2,1316}=667,2, \mathrm{P}<$ 0.001). Additionally, there was a significant interaction between exposure time and thermal regime such that females exposed to constant $3^{\circ} \mathrm{C}$ recovered slower as exposure time increased while females exposed to FTR recovered faster with prolonged exposure (two-way ANOVA, $\mathrm{F}_{2,1316}=$ 80.6, P < 0.001) (Fig. 5). Thus, FTR flies had the fastest recovery of all treatments and durations after having been exposed to FTR for 7 days (Fig. 5).

\section{Critical thermal maximum and minimum}

$\mathrm{CCO}$ and $\mathrm{HCO}$, also referred to as $\mathrm{CT}_{\min }$ and $\mathrm{CT}_{\max }$ in the literature, were tested in flies exposed for 27 days to either FTR or constant $25^{\circ} \mathrm{C}$ to examine if long-term storage affected heat and cold tolerance. There was no significant difference in $\mathrm{HCO}$ between female flies exposed to either constant $25^{\circ} \mathrm{C}$ or FTR (Mann-Whitney-Wilcoxon test, P>0.05), as flies from both regimes lost their ability to move around $38^{\circ} \mathrm{C}$ (Fig. 6A). In contrast female flies exposed to FTR were significantly more cold tolerant than females exposed to constant $25^{\circ} \mathrm{C}$ (Mann-Whitney-Wilcoxon test, $\mathrm{P}<0.001$ ), with a $\mathrm{CCO}$ of around $2.2^{\circ} \mathrm{C}$ for FTR females and of $5.6^{\circ} \mathrm{C}$ for $25^{\circ} \mathrm{C}$ females (Fig. 6B). FTR females seem therefore to conserve their heat tolerance and improving their cold tolerance during this treatment.

\section{Effect of storage conditions on hemolymph $\mathrm{K}^{+}$concentration of Drosophila suzukii}

Hemolymph potassium concentration was significantly affected by the thermal regime (two-way ANOVA, $\mathrm{df}=2, \mathrm{P}<0.001$ ), the duration of exposure (two-way ANOVA, $\mathrm{df}=6, \mathrm{P}<0.001$ ) and their interaction (two-way ANOVA, $\mathrm{df}=12, \mathrm{P}<0.001$ ). From $48 \mathrm{~h}$ of exposure, females subjected to constant $3^{\circ} \mathrm{C}$ had a significantly higher hemolymph potassium concentration than flies exposed to either constant $25^{\circ} \mathrm{C}$ or FTR. FTR females always maintained potassium concentration in the same range as the constant $25^{\circ} \mathrm{C}$ control flies (Fig. 7). 
Effect of storage conditions on body size and composition of Drosophila suzukii

\section{Wet mass}

For wet mass there was a significant interaction between the effects of thermal regime and duration of exposure (two-way ANOVA, $\mathrm{df}=10, \mathrm{P}<0.001$ ). Wet mass of flies exposed to constant $3^{\circ} \mathrm{C}$ was the lowest and decreased over the first 10 days (two-way ANOVA, df $=5, \mathrm{P}<0.001$ ) (Fig. 8a). During the prolonged exposure (40 days), the wet mass slightly decreases over time for constant $25^{\circ} \mathrm{C}$ and FTR flies (two-way ANOVA, $\mathrm{df}=11, \mathrm{P}<0.001$ ) (Fig. 8a) but we found no overall difference between these groups (two-way ANOVA, $\mathrm{df}=1, \mathrm{P}>0.05$ ). Therefore, FTR females were able to keep their mass constant and at the same level as constant $25^{\circ} \mathrm{C}$ females.

\section{Water content}

Water content of females varied between treatments (two-way ANOVA, df = 10, P<0.05). Flies exposed to constant $3^{\circ} \mathrm{C}$ were characterised by a decrease in water content during the first 10 days (two-way ANOVA, df = 5, P<0.001) (Fig. 8b). When examined over a 40 days period we found that water content of constant $25^{\circ} \mathrm{C}$ and FTR females differed (two-way ANOVA, $\mathrm{df}=1, \mathrm{P}<0.001$ ) but we also found that there were no statistical differences between these groups at either the first day of exposure or the last day. Therefore, constant $25^{\circ} \mathrm{C}$ flies and FTR females seem to conserve their water content over time (Fig. 8b).

\section{Lipid content}

Flies from the three thermal regimes differed in their lipid content (two-way ANOVA, df $=2$, $\mathrm{P}<0.01$ ) and lipid content also changed with duration of exposure (two-way ANOVA, df $=5$, $\mathrm{P}<0.001$ ) giving rise to a significant interaction between these factors (two-way ANOVA, $\mathrm{df}=10$, $\mathrm{P}<0.001$ ). Flies exposed to constant $3^{\circ} \mathrm{C}$ for 10 days were characterised by a slightly higher amount of lipid than flies exposed to constant $25^{\circ} \mathrm{C}$ or FTR. Both constant $25^{\circ} \mathrm{C}$ and FTR flies displayed a gradual decrease in lipid content (two-way ANOVA, df = 11, P<0.001) (Fig. 8c) but lipid content was not significantly different after 40 days of exposure (two-way ANOVA, $\mathrm{df}=1, \mathrm{P}>0.05$ ). Thus, FTR females seem to be also able to conserve their lipid content over time.

\section{Discussion}

Increased longevity and maintenance of fecundity 
Female flies exposed to FTR were characterised by a much longer longevity than flies reared at either constant 25 or $3^{\circ} \mathrm{C}$. $50 \%$ of FTR flies were still alive after 160 days, while all flies subjected to constant $25^{\circ} \mathrm{C}$ were found dead after 45 days and those exposed to constant $3^{\circ} \mathrm{C}$ survived only 10 days (Fig. 3). A similar difference in longevity has previously been observed by Koštál et al. (2016) who exposed larvae of D. melanogaster to either CLT or FTR treatments for 60 days and similar findings have also been shown to apply for adult D. suzukii stored for 120 days (Enriquez et al., 2018). Thus, the extended longevity of FTR flies compared to constant $3^{\circ} \mathrm{C}$ flies can be caused by the short warm periods allowing the repair of injury and the re-establishment of homeostasis during these periods (see discussion below). It could also be explained by the 'lower cold dose hypothesis' which posits that fewer chill injuries accumulate from day to day as insects under FTR are coldexposed for a relatively shorter cumulative period of time (Colinet et al., 2018). However considering that the cumulative cold exposure is many fold longer in the FTR flies after $>150$ days, this is not likely to contribute to differences in longevity between FTR and CLT groups. FTR flies did also live much longer than flies exposed to constant $25^{\circ} \mathrm{C}$. Thus, it is clear from our experiments that FTR treatments can harness the benefits of cold exposure where metabolic reactions and ageing are decelerated (Irlich et al., 2009; Pearl, 1928; Sohal, 1976) while simultaneously avoiding the injury related to chronic cold.

If FTR flies are destined to be used in biological control or experimentation it is important to examine if FTR flies have retained their characteristics, including their ability to reproduce. This is particularly relevant if stocks of D. suzukii are intended for use in sterile insect technique (SIT), which requires a rapid production of a large number of male flies to be released and out-compete wild populations. We therefore assessed the fecundity of flies exposed to either constant $25^{\circ} \mathrm{C}$ or FTR. FTR flies subjected for 40 days to their treatment were still able to lay eggs, while the egglaying rate of flies stored at constant $25^{\circ} \mathrm{C}$ was negligible after similar storage time (Fig. 4). Decreasing fecundity during ageing has already been observed by David et al. (1975) in $D$. melanogaster. Hence it appears that for Drosophila reared at warm temperatures fecundity rapidly increases and peaks in young flies (4-7 days for D. melanogaster but this is likely to vary among species) and then progressively declines resulting in infertility or reduced fecundity (Rauser et al., 2005). The mechanisms underlying this reproductive senescence are still not well understood, but reduced fecundity includes age-related changes in oogenesis and responses to the male seminal protein sex peptide (SP) (Miller et al., 2014; Tatar, 2010; Zhao et al., 2008). The preservation of fecundity in FTR flies is therefore consistent with the general postponement of senescence afforded 
by cold exposure. We emphasise that our findings of preserved fecundity are only a first step in the evaluation of FTR as a viable storage method. For example it is obviously of interest to examine the fitness of the resulting progeny, and previous studies have indicated that cold storage might alter the sex ratio of the progeny (Marshall and Sinclair, 2009).

It should also be noted that FTR females exposed for 10 or 20 days laid fewer eggs than those reared at constant $25^{\circ} \mathrm{C}$ for the same duration (Fig. 4). Similarly, Enriquez et al. (2018) found that FTR-exposed adults and pupae had a delayed and reduced cumulated egg production compared to controls. A reduction in fecundity could be caused by reallocation of energy resources like lipid or glycogen (Marshall and Sinclair, 2009), but since we found no difference in lipid stores between flies reared at FTR or constant $25^{\circ} \mathrm{C}$ this doesn't seem to apply to $D$. suzukii exposed to FTR (Fig. 8c). Reduction in fecundity of FTR flies could also be linked decreased ovarian size, as observed during reproductive diapause of D. melanogaster (Allen, 2007). However, FTR flies did not enter a true reproductive diapause, as they were able to resume egg laying soon after they were returned to permissive temperatures. Finally, it is possible that the repeated cold exposure causes some damage to the reproductive organs leading to an impairment of reproductive ability (Rinehart et al., 2000).

Maintenance of ion homeostasis and body composition allowed by intermittent heat exposure

It is believed that the benefits of FTR compared to CLT is related to the re-establishment of homeostasis during the short warm periods where metabolism is accelerated, and feeding/drinking is resumed (Colinet et al., 2015, 2018; Koštál et al., 2007). In the present study, we find clear support for this hypothesis as flies exposed to FTR were able to maintain their haemolymph potassium concentration $\left(\left[\mathrm{K}^{+}\right]_{\mathrm{o}}\right)$ at levels similar to the control flies at constant $25^{\circ} \mathrm{C}$. In contrast, flies subjected to CLT $\left(3^{\circ} \mathrm{C}\right)$ were characterised by a gradual increase in $\left[\mathrm{K}^{+}\right]_{\mathrm{o}}$ over the 7 day measurement period (Fig. 7). It is well described that dissipation of ion homeostasis, particularly potassium balance, is a hallmark of chill injury in insects (Koštál et al., 2004; Overgaard and MacMillan, 2017) including many drosophilid species (MacMillan et al., 2015a). At benign temperature, insects maintain ion balance through a regulated balance between active ion transport across cell membranes and epithelia that counterbalance the passive drift of ions along their electrochemical gradient (MacMillan and Sinclair, 2011; Overgaard and MacMillan, 2017). Exposure to chill-coma-inducing temperature depresses active transport, either by indirect effects on membrane fluidity or by directly decreasing the enzymatic activity, to a degree where active 
transport is insufficient to balance the passive leak (Denlinger and Lee, 2010; Koštál et al., 2007; Overgaard and MacMillan, 2017; Zachariassen et al., 2004). The resulting increase in $\left[\mathrm{K}^{+}\right]_{\mathrm{o}}$ depolarises the cells, initiating a debilitating cascade of events that cause cell death (Andersen et al., 2017; Bayley et al., 2018; Bortner et al., 2001; Overgaard and MacMillan, 2017). Thus, dramatic increases in $\left[\mathrm{K}^{+}\right]_{\mathrm{o}}$ in insects is both a sign of impaired homeostatic capacity and also an important mechanistic component of cellular cold injury.

FTR treatments have previously been shown to preserve ion homeostasis in P. apterus and A. diaperinus when the FTR animals were compared to conspecifics exposed to CLT (Koštál et al., 2007). In the study by Koštál et al. (2007), it was demonstrated that $\left[\mathrm{K}^{+}\right]_{\mathrm{o}}$ increased during the cold period, but then recovered back towards control values during the short warm period where active ion transport could return to its "normal" capacity and recover balance. This is also supported by MacMillan et al. (2012) and Findsen et al. (2014) who showed that cold disruption of haemolymph potassium concentration recovers rapidly towards control values within a 30 minute period at room temperature in G. pennsylvanicus and L. migratoria, respectively. In the present study, we observed a significant increase in $\left[\mathrm{K}^{+}\right]_{\mathrm{o}}$ in the CLT flies after $48 \mathrm{~h}$ whereas FTR flies maintain the same concentration over time (Fig. 7). It would thus be interesting to examine how long the cold period of an FTR cycle can be extended before a warm period must be allowed to re-establish ion homeostasis. Likewise, it would be of interest to examine how short a warm period can be to recover homeostasis. In this respect we suggest that $\left[\mathrm{K}^{+}\right]_{\mathrm{o}}$ could be used as an "homeostatic indicator" for such studies.

In addition to the maintenance of ion balance, we observed that the short warm period during FTR also allowed for the conservation of body mass and water balance while CLT caused loss of those parameters over time (Fig. 8). The decrease in body mass is largely explained by a loss of water in CLT flies. This water loss occurs even though low temperature decreases the drying power of the air (Harrison et al., 2012; Holmstrup et al., 2010) and despite respiratory water loss being reduced by the low metabolism of CLT individuals. Although the rate of water loss is seemingly low in CLT flies, it eventually becomes critical and these flies cannot replace water loss by drinking as they remain in a chill-coma during the constant $3^{\circ} \mathrm{C}$ exposure. On the contrary, FTR flies maintain their body mass and water and lipid content at the same level as constant $25^{\circ} \mathrm{C}$ flies (Fig. $8 \mathrm{~b}, 8 \mathrm{c})$. This conservation of mass and of water and lipid content was also been observed by Koštál et al. (2016) when comparing D. melanogaster larvae exposed to CLT or FTR (20h at $5^{\circ} \mathrm{C}$ or $6^{\circ} \mathrm{C}$ followed by $4 \mathrm{~h}$ at $\left.11^{\circ} \mathrm{C}\right)$. 


\section{Improvement of cold tolerance by acclimation}

Maintenance of flies at FTR led to a marked improvement of the flies' cold tolerance. FTR flies were able to recover faster from an acute cold stress (Fig. 5) and their $\mathrm{CCO}$ was approximatively $3^{\circ} \mathrm{C}$ lower than that of constant $25^{\circ} \mathrm{C}$ flies (Fig. 6b). This improvement of cold tolerance was not seen in CLT flies that were characterised by longer recovery (CCRT), presumably due to the gradual development of chill injury (Overgaard and MacMillan, 2017). This is supported by the large proportions of flies that failed to recovery within our 90 min time frame at a time point where mortality is high (see Fig. 3 and 5). Thus, FTR conditions are able to induce the beneficial effects of cold acclimation without acquiring the injury associated with chronic cold (Gibert and Huey, 2001; Rako and Hoffmann, 2006). In addition to the 'lower cold dose hypothesis' mentioned earlier, benefits brought by FTR could also be explained by the 'physiological recovery hypothesis' that assumes that homeostasis is re-established and chilling-injuries are repaired during warming intervals (Colinet et al., 2018). We believe that our data support the 'physiological recovery hypothesis' but the superior condition of the FTR flies also supports a 'gradual acclimation hypothesis' where flies under FTR may suffer less chill injury due to a gradual cold acclimation. Improvement of cold tolerance as a result of cold acclimation has already been described repeatedly in insects, including Drosophila (Colinet and Hoffmann, 2012; Gibert and Huey, 2001; Hori and Kimura, 1998; Rako and Hoffmann, 2006). The exposure to numerous cycles of alternating cold and warm temperature has also been shown to improve thermal tolerance to acute cold shock and to lowers CCO in adult D. melanogaster (Kelty and Lee, 2001). It is therefore likely that FTR treatments initiate many of the beneficial physiological responses associated with cold acclimation in Drosophila. These include, modifications of membrane lipid composition (Colinet et al., 2016; Hazel, 1995; Overgaard et al., 2005), small increases in cryo- or cytoprotective osmolytes (Koštál et al., 2016; MacMillan et al., 2015b) as well as some modification in gene transcription (Storey and Storey, 2012; Teets and Denlinger, 2013; Torson et al., 2015).

We also tested if FTR altered heat tolerance of D. suzukii females. This was assessed as heat coma onset temperature ( $\mathrm{HCO}$ - also referred to as $\mathrm{CT}_{\max }$ in some studies) (Fig. 6a). We found no difference in $\mathrm{HCO}$ between FTR and constant $25^{\circ} \mathrm{C}$, which is generally characterised by low plasticity in Drosophila (Sørensen et al., 2016). Maintenance of a constant HCO in insects exposed to FTR suggests that the increase in cold tolerance does not come at an immediate cost in in heat tolerance which may prove useful if FTR reared insects are to be released in areas with variable and 
occasional high temperatures. However, further studies are needed to validate that FTR treatments are not associated with general cost or trade-offs in terms of stress tolerance and performance.

\section{Conclusion}

Individuals exposed to FTR displayed extended longevity, preservation of fecundity for $>40$ days of age, maintenance of the ion homeostasis, conservation of body mass, water and lipid content and improved cold tolerance. These findings support the use of FTR as a potential storage method in chill-susceptible species, as FTR treated flies avoid the drawbacks of colony maintenance in terms of senescence and simultaneously avoids chill-injury to the cold exposed flies. Our study generally suggests that FTR represents a practical and efficient protocol for long-term and non-damaging insect storage. Such storage could be relevant in the management of pests such as D. suzukii, particularly with SIT, where great numbers are needed for simultaneous release in invaded areas. Prolonged exposure to low temperature can, however, affect an organism in other ways than the ones investigated here. It would therefore be of interest to investigate putative trade-offs further to examine if FTR represents a reliable solution for long-term insect storage.

\section{Acknowledgements}

We would like to thank Kirsten Kromand for help with fly maintenance and with laboratory experiments in general. The research and activities of C.G, M.K.A. and J.O. was funded by a grant from the Danish Council for Independent Research | Natural Sciences (Det Frie Forskningsråd | Natur og Univers) and activities of H.C was supported by SUZUKILL project (Agence Nationale de la Recherche: ANR15-CE21-0017-01 and Austrian Science Fund: FWF-I2604-B25). 


\section{Reference list}

Allen, M., 2007. What Makes a Fly Enter Diapause? Fly (Austin) 1, 307-310. https://doi.org/10.4161/fly.5532

Andersen, J.L., MacMillan, H.A., Overgaard, J., 2015. Muscle membrane potential and insect chill coma. J. Exp. Biol. 218, 2492-2495. https://doi.org/10.1242/jeb.123760

Andersen, M.K., Folkersen, R., MacMillan, H.A., Overgaard, J., 2017. Cold acclimation improves chill tolerance in the migratory locust through preservation of ion balance and membrane potential. J. Exp. Biol. 220, 487-496. https://doi.org/10.1242/jeb.150813

Ascunce, M.S., Yang, C.-C., Oakey, J., Calcaterra, L., Wu, W.-J., Shih, C.-J., Goudet, J., Ross, K.G., Shoemaker, D., 2011. Global Invasion History of the Fire Ant Solenopsis invicta. Science 331, 1066-1068. https://doi.org/10.1126/science.1198734

Bayley, J.S., Winther, C.B., Andersen, M.K., Grønkjær, C., Nielsen, O.B., Pedersen, T.H., Overgaard, J., 2018. Cold exposure causes cell death by depolarization-mediated $\mathrm{Ca} 2+$ overload in a chill-susceptible insect. Proc. Natl. Acad. Sci. 115, E9737-E9744. https://doi.org/10.1073/pnas.1813532115

Boardman, L., Sørensen, J.G., Terblanche, J.S., 2013. Physiological responses to fluctuating thermal and hydration regimes in the chill susceptible insect, Thaumatotibia leucotreta. J. Insect Physiol. 59, 781-794. https://doi.org/10.1016/j.jinsphys.2013.05.005

Bolda, M.P., Goodhue, R.E., Zalom, F.G., 2010. Spotted Wing Drosophila: Potential Economic Impact of a Newly Established Pest. Univ. Calif. Giannini Found. Agric. Econ. 13, 4.

Bortner, C.D., Gomez-Angelats, M., Cidlowski, J.A., 2001. Plasma membrane depolarization without repolarization is an early molecular event in anti-Fas-induced apoptosis. J. Biol. Chem. 276, 4304-4314. https://doi.org/10.1074/jbc.M005171200

Cini, A., Ioriatti, C., Anfora, G., 2012. A review of the invasion of Drosophila suzukii in Europe and a draft research agenda for integrated pest management. Bull. INSECTOLOGY 65, $149-160$.

Colinet, H., Hance, T., 2009. Male Reproductive Potential of Aphidius colemani (Hymenoptera: Aphidiinae) Exposed to Constant or Fluctuating Thermal Regimens. Environ. Entomol. 38, 242-249. https://doi.org/10.1603/022.038.0130

Colinet, H., Hoffmann, A.A., 2012. Comparing phenotypic effects and molecular correlates of developmental, gradual and rapid cold acclimation responses in Drosophila melanogaster. Funct. Ecol. 26, 84-93. https://doi.org/10.1111/j.1365-2435.2011.01898.x

Colinet, H., Renault, D., Javal, M., Berková, P., Šimek, P., Koštál, V., 2016. Uncovering the benefits of fluctuating thermal regimes on cold tolerance of drosophila flies by combined metabolomic and lipidomic approach. Biochim. Biophys. Acta BBA - Mol. Cell Biol. Lipids 1861, 1736-1745. https://doi.org/10.1016/j.bbalip.2016.08.008

Colinet, H., Rinehart, J.P., Yocum, G.D., Greenlee, K.J., 2018. Mechanisms underpinning the beneficial effects of fluctuating thermal regimes in insect cold tolerance. J. Exp. Biol. 221, jeb164806. https://doi.org/10.1242/jeb.164806

Colinet, H., Sinclair, B.J., Vernon, P., Renault, D., 2015. Insects in Fluctuating Thermal Environments. Annu. Rev. Entomol. 60, 123-140. https://doi.org/10.1146/annurev-ento010814-021017

Curtsinger, J.W., 2013. Late-life fecundity plateaus in Drosophila melanogaster can be explained by variation in reproductive life spans. Exp. Gerontol. 48, 1338-1342. https://doi.org/10.1016/j.exger.2013.08.016

Dalton, D.T., Walton, V.M., Shearer, P.W., Walsh, D.B., Caprile, J., Isaacs, R., 2011. Laboratory survival of Drosophila suzukii under simulated winter conditions of the Pacific Northwest 
and seasonal field trapping in five primary regions of small and stone fruit production in the United States. Pest Manag. Sci. 67, 1368-1374. https://doi.org/10.1002/ps.2280

David, J., Cohet, Y., Fouillet, P., 1975. The variability between individuals as a measure of senescence: A study of the number of eggs laid and the percentage of hatched eggs in the case of Drosophila melanogaster. Exp. Gerontol. 10, 17-25. https://doi.org/10.1016/05315565(75)90011-X

Denlinger, D.L., Lee, R.E., 2010. Low Temperature Biology of Insects. Cambridge University Press.

Desneux, N., Wajnberg, E., Wyckhuys, K.A.G., Burgio, G., Arpaia, S., Narváez-Vasquez, C.A., González-Cabrera, J., Ruescas, D.C., Tabone, E., Frandon, J., Pizzol, J., Poncet, C., Cabello, T., Urbaneja, A., 2010. Biological invasion of European tomato crops by Tuta absoluta: ecology, geographic expansion and prospects for biological control. J. Pest Sci. 83, 197-215. https://doi.org/10.1007/s10340-010-0321-6

Enriquez, T., Colinet, H., 2017. Basal tolerance to heat and cold exposure of the spotted wing drosophila, Drosophila suzukii. PeerJ 5, e3112. https://doi.org/10.7717/peerj.3112

Enriquez, T., Ruel, D., Charrier, M., Colinet, H., 2018. Effects of fluctuating thermal regimes on cold survival and life history traits of the spotted wing Drosophila (Drosophila suzukii, Matsumara). Insect Sci. https://doi.org/10.1111/1744-7917.12649

Findsen, A., Pedersen, T.H., Petersen, A.G., Nielsen, O.B., Overgaard, J., 2014. Why do insects enter and recover from chill coma? Low temperature and high extracellular potassium compromise muscle function in Locusta migratoria. J. Exp. Biol. 217, 1297-1306. https://doi.org/10.1242/jeb.098442

Gibert, P., Huey, R.B., 2001. Chill-coma temperature in Drosophila: effects of developmental temperature, latitude, and phylogeny. Physiol. Biochem. Zool. PBZ 74, 429-434. https://doi.org/10.1086/320429

Goodhue, R.E., Bolda, M., Farnsworth, D., Williams, J.C., Zalom, F.G., 2011. Spotted wing drosophila infestation of California strawberries and raspberries: economic analysis of potential revenue losses and control costs. Pest Manag. Sci. 67, 1396-1402. https://doi.org/10.1002/ps.2259

Harrison, J.F., Woods, H.A., Roberts, S.P., 2012. Ecological and Environmental Physiology of Insects. Oxford University Press.

Hazel, J.R., 1995. Thermal adaptation in biological membranes: is homeoviscous adaptation the explanation? Annu. Rev. Physiol. 57, 19-42. https://doi.org/10.1146/annurev.ph.57.030195.000315

Hendrichs, J., Robinson, A., 2009. Chapter 243 - Sterile Insect Technique, in: Resh, V.H., Cardé, R.T. (Eds.), Encyclopedia of Insects (Second Edition). Academic Press, San Diego, pp. 953957. https://doi.org/10.1016/B978-0-12-374144-8.00252-6

Holmstrup, M., Bayley, M., Pedersen, S.A., 2010. Interactions between cold, desiccation and environmental toxins, in: Low Temperature Biology of Insects. David L. Denlinger, Richard E. Lee Jr, pp. 166-187.

Hori, Y. (Hokkaido U., Kimura, M.T., 1998. Relationship between cold stupor and cold tolerance in Drosophila (Diptera: Drosophilidae). Environ. Entomol. USA.

Irlich, U.M., Terblanche, J.S., Blackburn, T.M., Chown, S.L., 2009. Insect Rate- Temperature Relationships: Environmental Variation and the Metabolic Theory of Ecology. Am. Nat. 174, 819-835. https://doi.org/10.1086/647904

Jakobs, R., Gariepy, T.D., Sinclair, B.J., 2015. Adult plasticity of cold tolerance in a continentaltemperate population of Drosophila suzukii. J. Insect Physiol. 79, 1-9. https://doi.org/10.1016/j.jinsphys.2015.05.003 
Javal, M., Renault, D., Colinet, H., 2016. Impact of fluctuating thermal regimes on Drosophila melanogaster survival to cold stress. Anim. Biol. 66, 427-444. https://doi.org/10.1163/15707563-00002510

Kanzawa, T., 1939. Studies on Drosophila suzukii Mats. Stud. Drosoph. Suzukii Mats.

Kelty, J.D., Lee, R.E., 2001. Rapid cold-hardening of Drosophila melanogaster (Diptera: Drosophiladae) during ecologically based thermoperiodic cycles. J. Exp. Biol. 204, 16591666.

Kimura, M.T., 2004. Cold and heat tolerance of drosophilid flies with reference to their latitudinal distributions. Oecologia 140, 442-449. https://doi.org/10.1007/s00442-004-1605-4

Koštál, V., Korbelová, J., Štětina, T., Poupardin, R., Colinet, H., Zahradníčková, H., Opekarová, I., Moos, M., Šimek, P., 2016. Physiological basis for low-temperature survival and storage of quiescent larvae of the fruit fly Drosophila melanogaster. Sci. Rep. 6, 32346. https://doi.org/10.1038/srep32346

Koštál, V., Renault, D., Mehrabianová, A., Bastl, J., 2007. Insect cold tolerance and repair of chillinjury at fluctuating thermal regimes: Role of ion homeostasis. Comp. Biochem. Physiol. A. Mol. Integr. Physiol. 147, 231-238. https://doi.org/10.1016/j.cbpa.2006.12.033

Koštál, V., Vambera, J., Bastl, J., 2004. On the nature of pre-freeze mortality in insects: water balance, ion homeostasis and energy charge in the adults of Pyrrhocoris apterus. J. Exp. Biol. 207, 1509-1521. https://doi.org/10.1242/jeb.00923

Lee, J.C., Bruck, D.J., Dreves, A.J., Ioriatti, C., Vogt, H., Baufeld, P., 2011. In Focus: Spotted wing drosophila, Drosophila suzukii, across perspectives. Pest Manag. Sci. 67, 1349-1351. https://doi.org/10.1002/ps.2271

Lin, Q.-C., Zhai, Y.-F., Zhang, A.-S., Men, X.-Y., Zhang, X.-Y., Zalom, F.G., Zhou, C.-G., Yu, Y., 2014. Comparative Developmental Times and Laboratory Life Tables for Drosophlia suzukii and Drosophila melanogaster (Diptera: Drosophilidae). Fla. Entomol. 97, 1434-1442. https://doi.org/10.1653/024.097.0418

Luque de Castro, M.D., Priego-Capote, F., 2010. Soxhlet extraction: Past and present panacea. J. Chromatogr. A, Extraction Techniques 1217, 2383-2389. https://doi.org/10.1016/j.chroma.2009.11.027

MacMillan, H.A., Andersen, J.L., Davies, S.A., Overgaard, J., 2015a. The capacity to maintain ion and water homeostasis underlies interspecific variation in Drosophila cold tolerance. Sci. Rep. 5. https://doi.org/10.1038/srep18607

MacMillan, H.A., Andersen, J.L., Loeschcke, V., Overgaard, J., 2015b. Sodium distribution predicts the chill tolerance of Drosophila melanogaster raised in different thermal conditions. Am. J. Physiol. - Regul. Integr. Comp. Physiol. 308, R823-R831. https://doi.org/10.1152/ajpregu.00465.2014

MacMillan, H.A., Baatrup, E., Overgaard, J., 2015c. Concurrent effects of cold and hyperkalaemia cause insect chilling injury. Proc. Biol. Sci. 282, 20151483. https://doi.org/10.1098/rspb.2015.1483

MacMillan, H.A., Hughson, B.N., 2014. A high-throughput method of hemolymph extraction from adult Drosophila without anesthesia. J. Insect Physiol. 63, 27-31. https://doi.org/10.1016/j.jinsphys.2014.02.005

MacMillan, H.A., Sinclair, B.J., 2011. Mechanisms underlying insect chill-coma. J. Insect Physiol. 57, 12-20. https://doi.org/10.1016/j.jinsphys.2010.10.004

MacMillan, H.A., Williams, C.M., Staples, J.F., Sinclair, B.J., 2012. Reestablishment of ion homeostasis during chill-coma recovery in the cricket Gryllus pennsylvanicus. Proc. Natl. Acad. Sci. U. S. A. 109, 20750-20755. https://doi.org/10.1073/pnas.1212788109 
Marshall, K.E., Sinclair, B.J., 2009. Repeated stress exposure results in a survival-reproduction trade-off in Drosophila melanogaster. Proc. R. Soc. Lond. B Biol. Sci. rspb20091807. https://doi.org/10.1098/rspb.2009.1807

Miller, P.B., Obrik-Uloho, O.T., Phan, M.H., Medrano, C.L., Renier, J.S., Thayer, J.L., Wiessner, G., Bloch Qazi, M.C., 2014. The song of the old mother: reproductive senescence in female drosophila. Fly (Austin) 8, 127-139. https://doi.org/10.4161/19336934.2014.969144

Nedved, O., Lavy, D., Verhoef, H.A., 1998. Modelling the time-temperature relationship in cold injury and effect of high-temperature interruptions on survival in a chill-sensitive collembolan. Funct. Ecol. 12, 816-824. https://doi.org/10.1046/j.1365-2435.1998.00250.x

Nikolouli, K., Colinet, H., Renault, D., Enriquez, T., Mouton, L., Gibert, P., Sassu, F., Cáceres, C., Stauffer, C., Pereira, R., Bourtzis, K., 2017. Sterile insect technique and Wolbachia symbiosis as potential tools for the control of the invasive species Drosophila suzukii. J. Pest Sci. 91. https://doi.org/10.1007/s10340-017-0944-y

Overgaard, J., MacMillan, H.A., 2017. The Integrative Physiology of Insect Chill Tolerance. Annu. Rev. Physiol. 79, 187-208. https://doi.org/10.1146/annurev-physiol-022516-034142

Overgaard, J., Sørensen, J.G., Petersen, S.O., Loeschcke, V., Holmstrup, M., 2005. Changes in membrane lipid composition following rapid cold hardening in Drosophila melanogaster. J. Insect Physiol. 51, 1173-1182. https://doi.org/10.1016/j.jinsphys.2005.06.007

Pearl, R., 1928. The Rate Of Living. By Alfred A.Knopf Inc.

Plantamp, C., Salort, K., Gibert, P., Dumet, A., Mialdea, G., Mondy, N., Voituron, Y., 2016. All or nothing: Survival, reproduction and oxidative balance in Spotted Wing Drosophila (Drosophila suzukii) in response to cold. J. Insect Physiol. 89, 28-36. https://doi.org/10.1016/j.jinsphys.2016.03.009

Rako, L., Hoffmann, A.A., 2006. Complexity of the cold acclimation response in Drosophila melanogaster. J. Insect Physiol. 52,94-104. https://doi.org/10.1016/j.jinsphys.2005.09.007

Rauser, C.L., Abdel-Aal, Y., Shieh, J.A., Suen, C.W., Mueller, L.D., Rose, M.R., 2005. Lifelong heterogeneity in fecundity is insufficient to explain late-life fecundity plateaus in Drosophila melanogaster. Exp. Gerontol. 40, 660-670. https://doi.org/10.1016/j.exger.2005.06.006

Renault D., Nedved O., Hervant F., Vernon P., 2004. The importance of fluctuating thermal regimes for repairing chill injuries in the tropical beetle Alphitobius diaperinus (Coleoptera: Tenebrionidae) during exposure to low temperature. Physiol. Entomol. 29, 139-145. https://doi.org/10.1111/j.0307-6962.2004.00377.x

Rinehart, J.P., Yocum, G.D., Denlinger, D.L., 2000. Thermotolerance and rapid cold hardening ameliorate the negative effects of brief exposures to high or low temperatures on fecundity in the flesh fly, Sarcophaga crassipalpis. Physiol. Entomol. 25, 330-336. https://doi.org/10.1111/j.1365-3032.2000.00201.x

Ryan, G.D., Emiljanowicz, L., Wilkinson, F., Kornya, M., Newman, J.A., 2016. Thermal Tolerances of the Spotted-Wing Drosophila Drosophila suzukii (Diptera: Drosophilidae). J. Econ. Entomol. 109, 746-752. https://doi.org/10.1093/jee/tow006

Sohal, R.S., 1976. Metabolic Rate and Life Span. Cell. Ageing Concepts Mech. 9, 25-40. https://doi.org/10.1159/000398915

Sørensen, J.G., Kristensen, T.N., Overgaard, J., 2016. Evolutionary and ecological patterns of thermal acclimation capacity in Drosophila: is it important for keeping up with climate change? Curr. Opin. Insect Sci., Global change biology * Molecular physiology 17, 98-104. https://doi.org/10.1016/j.cois.2016.08.003

Storey, K.B., Storey, J.M., 2012. Insect cold hardiness: metabolic, gene, and protein adaptation1This review is part of a virtual symposium on recent advances in understanding a variety of complex regulatory processes in insect physiology and endocrinology, including 
development, metabolism, cold hardiness, food intake and digestion, and diuresis, through the use of omics technologies in the postgenomic era. Can. J. Zool. 90, 456-475. https://doi.org/10.1139/z2012-011

Tatar, M., 2010. Reproductive aging in invertebrate genetic models. Ann. N. Y. Acad. Sci. 1204, 149-155. https://doi.org/10.1111/j.1749-6632.2010.05522.x

Teets, N., Denlinger, D., 2013. Physiological mechanisms of seasonal and rapid cold-hardening in insects. Physiol. Entomol. 38, 105-116. https://doi.org/10.1111/phen.12019

Torson, A.S., Yocum, G.D., Rinehart, J.P., Kemp, W.P., Bowsher, J.H., 2015. Transcriptional responses to fluctuating thermal regimes underpinning differences in survival in the solitary bee Megachile rotundata. J. Exp. Biol. 218, 1060-1068. https://doi.org/10.1242/jeb.113829

Zabalou, S., Apostolaki, A., Livadaras, I., Franz, G., Robinson, A.S., Savakis, C., Bourtzis, K., 2009. Incompatible insect technique: incompatible males from a Ceratitis capitata genetic sexing strain. Entomol. Exp. Appl. 132, 232-240. https://doi.org/10.1111/j.15707458.2009.00886.x

Zachariassen, K.E., Kristiansen, E., Pedersen, S.A., 2004. Inorganic ions in cold-hardiness. Cryobiology, Special issue: Keynote papers from CRYOBIOMOL- 2003 48, 126-133. https://doi.org/10.1016/j.cryobiol.2004.01.004

Zhao, R., Xuan, Y., Li, X., Xi, R., 2008. Age-related changes of germline stem cell activity, niche signaling activity and egg production in Drosophila. Aging Cell 7, 344-354.

https://doi.org/10.1111/j.1474-9726.2008.00379.x 


\section{Figure legends}

Figure 1. Temperature regimes used for experiments. From top to bottom: A 12/12 Light:Dark cycle was used for all temperature regimes; 1: constant $25^{\circ} \mathrm{C}$; 2: FTR alternating 20 hours of constant $3^{\circ} \mathrm{C}$ and $1 \mathrm{~h} 20 \mathrm{~min}$ of constant $25^{\circ} \mathrm{C}$ with $1 \mathrm{~h} 20 \mathrm{~min}$ of heating/cooling in between; 3 : constant $3^{\circ} \mathrm{C}$. For figures in color see online version.

Figure 2 Sampling timeline representing the period during which Drosophila suzukii females were exposed to either constant $25^{\circ} \mathrm{C}$ (red marks), constant $3^{\circ} \mathrm{C}$ (blue marks) or FTR (purple marks). The first timeline represents sampling times for longevity only (triangles) or longevity and fecundity (egg-shaped marks). Crosses show time points when survival was $0 \%$. The second timeline shows when thermal tolerance assays were measured (circles). The third timeline show sampling times for haemolymph potassium concentration (squares). The fourth timeline indicate when body size, water and lipid content was assessed (diamonds). For figures in color see online version.

Figure 3 Longevity of Drosophila suzukii females exposed to constant $25^{\circ} \mathrm{C}$ (red circles), constant $3^{\circ} \mathrm{C}$ (blue diamonds) or FTR (purple triangles). Constant $25^{\circ} \mathrm{C}: \mathrm{N}=200$; Constant $3^{\circ} \mathrm{C}: \mathrm{N}=1000$; FTR: $\mathrm{N}=200$ (see methods for details). For figures in color see online version.

Figure 4 Boxplot representing the number of eggs laid by Drosophila suzukii females following exposure to constant $25^{\circ} \mathrm{C}$ (red boxes) or FTR (purple boxes) for 10, 20, 30 or 40 days. The line in the centre of the box represents a median value, the top and bottom of the box represent 25th and 75th percentiles. Whiskers represent minimum and maximum values excluding points outside the 95\% confidence intervals (these points are presented as black dots). $\mathrm{N}=10$ females per temperature and duration combination. Dissimilar letters indicate groups which differ significantly between and within treatment groups. For figures in color see online version.

Figure 5 Chill-coma recovery time of Drosophila suzukii females subjected to constant $25^{\circ} \mathrm{C}$ (red circles), constant $3^{\circ} \mathrm{C}$ (blue diamonds) and FTR (purple triangles) temperature treatments for 1 to 7 days and after a $14 \mathrm{~h} 0^{\circ} \mathrm{C}$ bath; $\mathrm{N}=90 \pm 10$ for each thermal treatment. Numbers above each dot represent the percentage of individuals still in coma after 90 minutes at $25^{\circ} \mathrm{C}$. For figures in color see online version. 
Figure 6. Temperature of heat coma onset (A) and chill coma onset (B) of Drosophila suzukii females after exposure to constant $25^{\circ} \mathrm{C}$ (red box) or FTR (purple box) for 27 days. The line in the centre of the box represents the median, top and bottom of box represent 25 th and 75 th percentiles, whiskers represent minimum and maximum values excluding points that fall outside $95 \%$ confidence intervals (these are represented as black dots). $\mathrm{N}=20$ for each temperature treatment. Asterisk indicate a significant difference between rearing temperature regime. For figures in color see online version.

Figure 7. Potassium concentration of haemolymph from Drosophila suzukii females exposed to either constant $25^{\circ} \mathrm{C}$ (red circles), constant $3{ }^{\circ} \mathrm{C}$ (blue diamonds) or FTR (purple triangles). Constant $25^{\circ} \mathrm{C}: \mathrm{N}=15$ per time of exposure; constant $3{ }^{\circ} \mathrm{C}: \mathrm{N}=12 \pm 3$ per time of exposure; FTR: $\mathrm{N}=15$ per time of exposure. Errors bars represent the standard error and dissimilar letters indicate groups which differ significantly between and within treatment groups. For figures in color see online version.

Figure 8 Wet mass (A), water (B) and lipid content (C) of Drosophila suzukii females exposed to either constant $25^{\circ} \mathrm{C}$ (red circles), constant $3^{\circ} \mathrm{C}$ (blue diamonds) or FTR (purple triangles) for 0 to 40 days. $\mathrm{N}=60 \pm 5$ per thermal regime and duration of exposure. Error bars represent the standard error. For figures in color see online version. 
1 Constant $25^{\circ} \mathrm{C}$

\section{$25^{\circ} \mathrm{C}$}

Fluctuating

2 thermal regime (FTR)

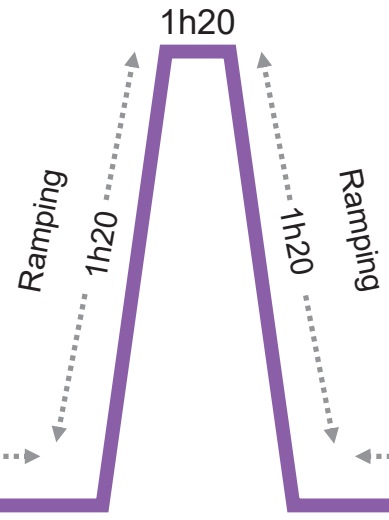




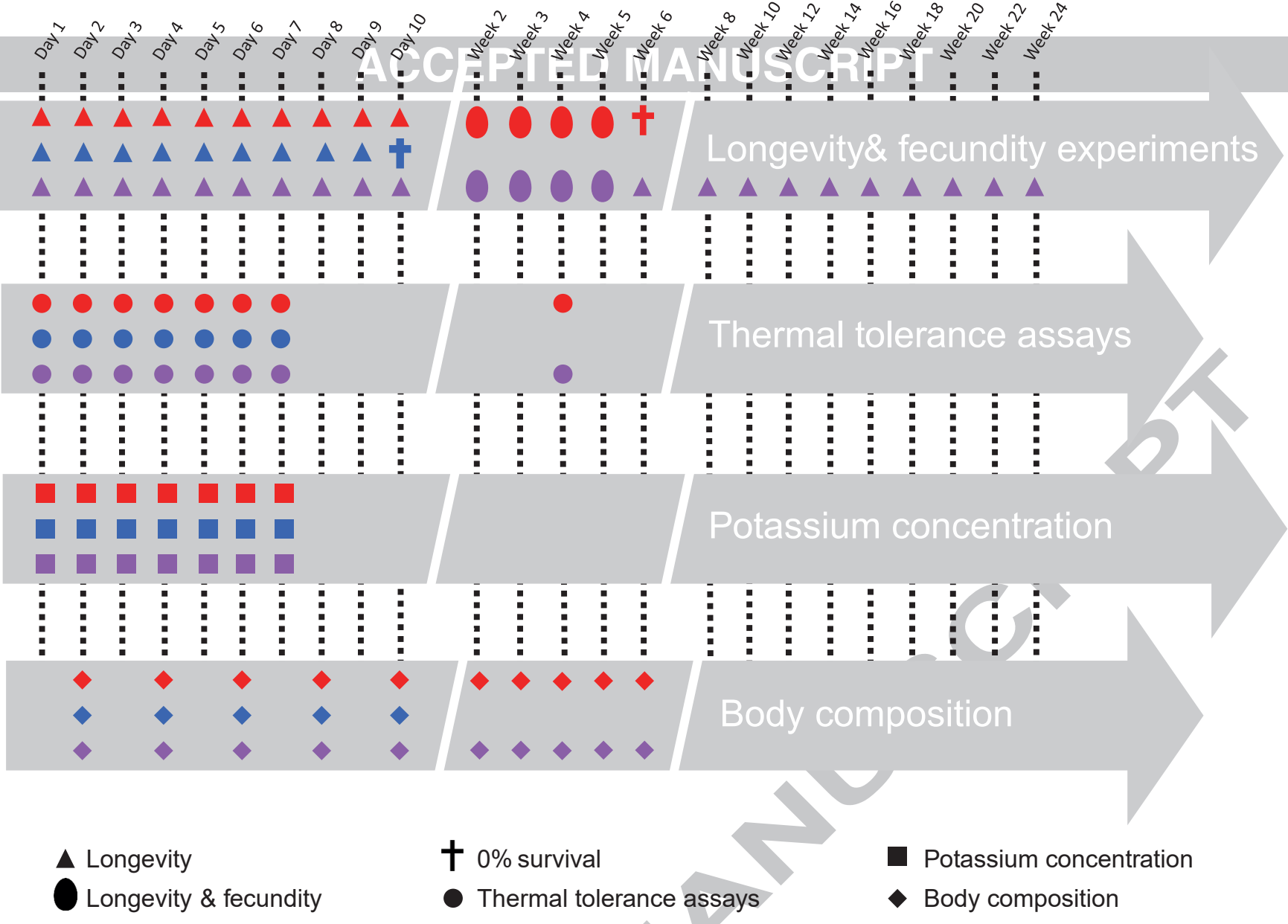




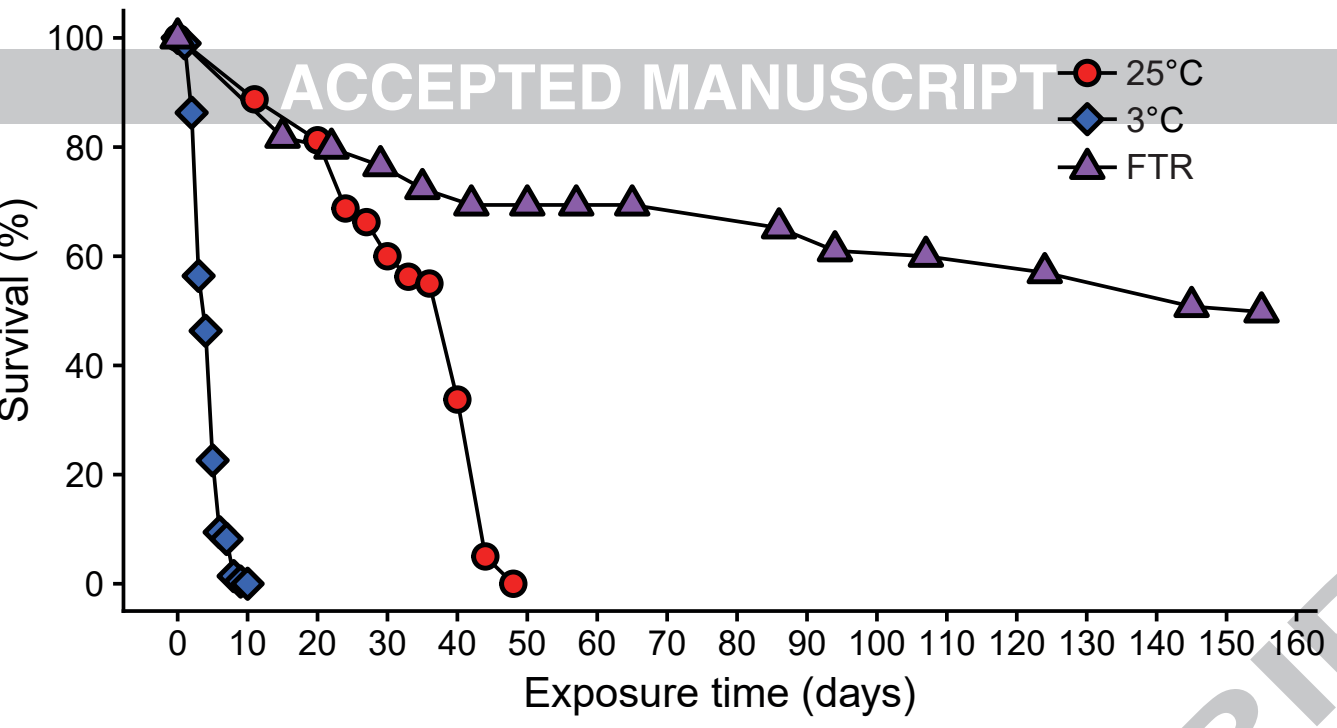




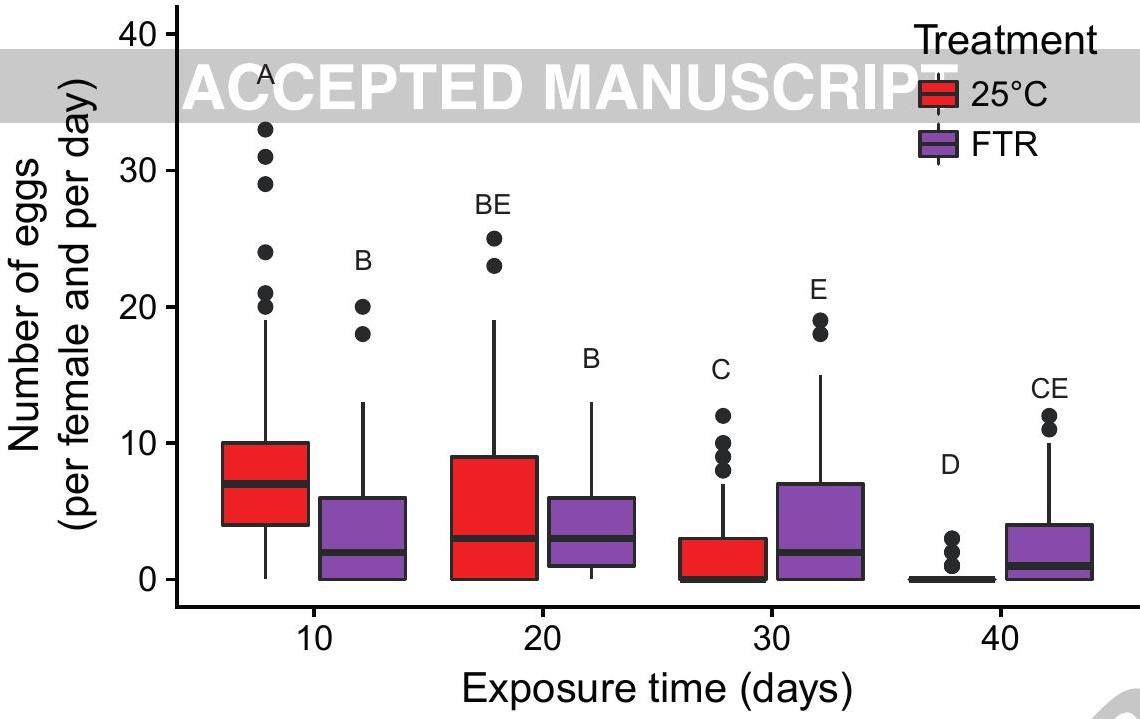




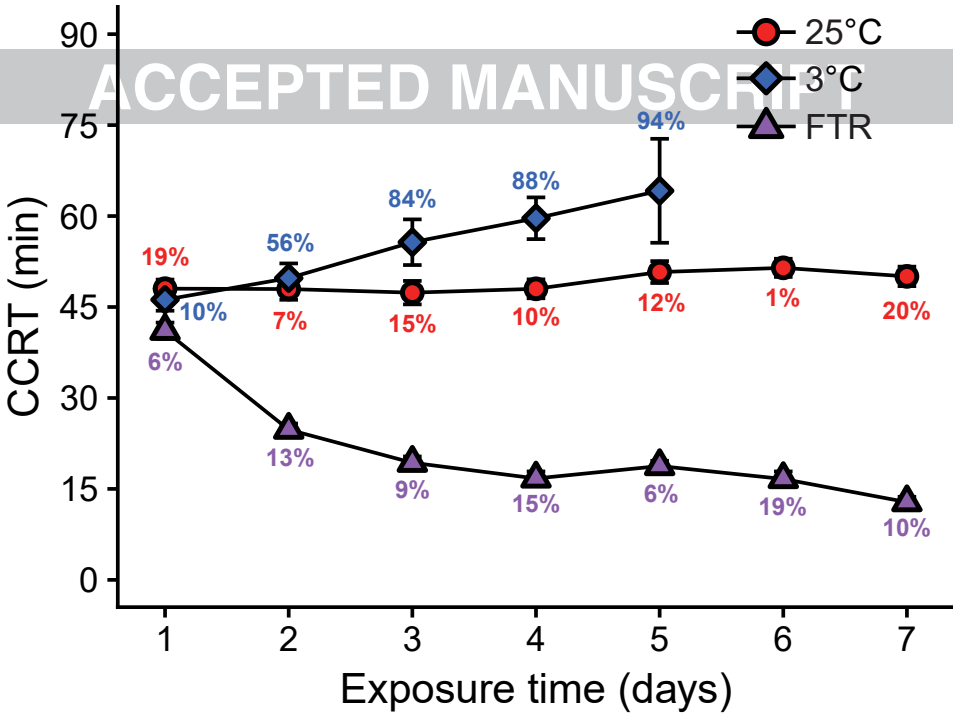




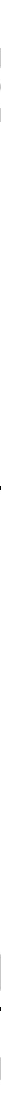




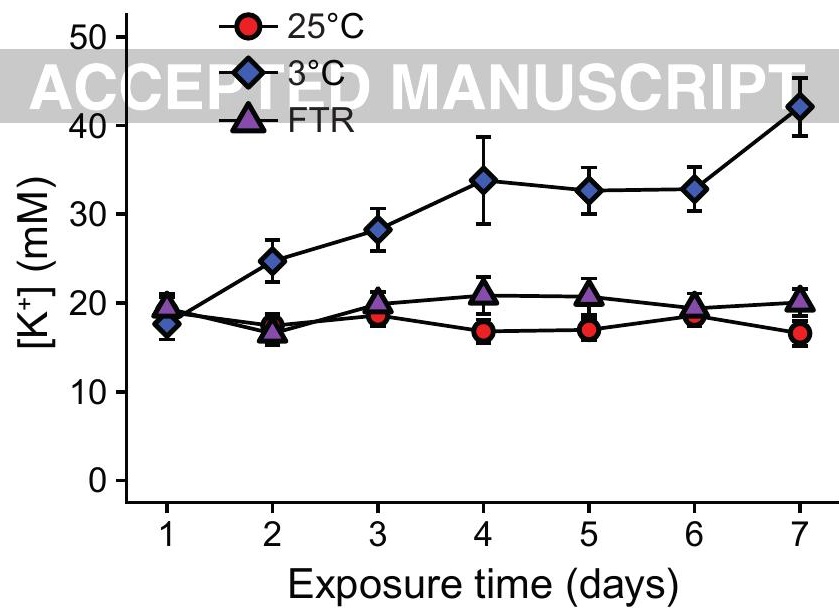



Fluctuating thermal regime (FTR)
Longevity

A

Constant low temperature

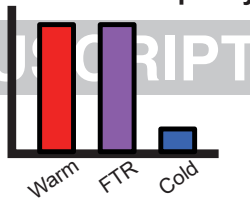

Early fecundity

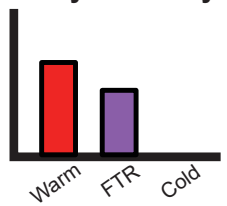

Late fecundity

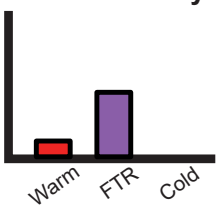




\section{Highlights}

- $\quad$ Adult D. suzukii were exposed to warm, cold or fluctuating thermal regimes (FTR)

- FTR treatment cycled between long cold periods (20h) and short warm periods (1.3h)

- Flies at constant cold lost extracellular ion-balance and died of chill injury

- Flies at constant warm experienced a progressive reduction in fecundity and survival

- FTR flies preserved ion homeostasis and secured long term survival and fecundity 